\title{
Memorable conversations in neonatal intensive care: A qualitative analysis of interprofessional provider perspectives
}

\author{
Dara Brodsky $^{1,2}$, Giulia Lamiani ${ }^{3}$, Olyn Andrade ${ }^{2}$, Victor M J ohnson ${ }^{4}$, Donna Luff ${ }^{5}$, Elaine C Meyer ${ }^{6}$ \\ 1. Department of Neonatology, Beth Israel Deaconess Medical Center, Boston, MA. 2. Institute for Professionalism \& \\ Ethical Practice, Boston Children's Hospital, Boston, MA. 3. Department of Medicine, Surgery and Dentistry, University of \\ Milan, Milan, Italy. 4. Department of Anesthesiology, Perioperative \& Pain Medicine, Boston Children's Hospital, Boston, \\ MA. 5. Pediatric Health Services Research Fellowship Program, Boston Children's Hospital, Boston, MA. 6. Department of \\ Psychiatry, Harvard Medical School, Boston, MA.
}

Correspondence: Dara Brodsky. Address: Department of Neonatology, Beth Israel Deaconess Medical Center, Rose 3, 330 Brookline Avenue, Boston, MA. Email: dbrodsky@bidmc.harvard.edu

Received: July 30, 2013

DOI : $10.5430 /$ jnep.v4n3p38
Accepted: September 10, 2013

URL: http://dx.doi.org/10.5430/jnep.v4n3p38

\section{Abstract}

Objective: In this study, we explored the providers' perspective of difficult conversations in neonatal critical care.

Methods: Between 2008 and 2011, interprofessional neonatal providers voluntarily attended the Program to Enhance Relational and Communication Skills-NICU workshops at Boston Children's Hospital. We analyzed seventy-four participant narratives that described a difficult conversation in the NICU that was particularly challenging or satisfying.

Results: Participants described memorable conversations that were exclusively challenging ( $n=51)$, both challenging and satisfying $(\mathrm{n}=22)$, and exclusively satisfying $(\mathrm{n}=1)$. We identified five broad domains (Infant's Clinical Situation, Family Characteristics, Provider Characteristics, the Provider-Family Relationship, and Satisfying Elements) and several themes that further characterized the providers' perspectives.

Conclusion: Understanding the practitioners' experience with difficult conversations may help staff to anticipate some challenges inherent in neonatal discussions and to design communication and relational learning educational efforts.

\section{Key words}

Neonatology, Communication skills, Difficult conversations, Professional-patient relations, Interprofessional learning

\section{I ntroduction}

Neonatal practitioners are often responsible for conveying difficult information to families of patients in the neonatal intensive care unit (NICU) ${ }^{[1-3]}$. These difficult conversations can be defined as a verbal communication that a health care professional finds hard to discuss; the degree of difficulty of a conversation is determined by the content, the recipient, and/or the provider's mindset at the time of the discussion. The scope of NICU providers involved in difficult conversations is large, encompassing physicians, nurses, respiratory therapists, and psychosocial personnel, with practitioners conveying clinical information and providing emotional support to families. The challenging interactions include discussions about an infant's survival, abnormal study results, complications of prematurity, uncertain neurodevelop- 
mental outcomes, and withholding or withdrawing life-sustaining treatments. Conversations are particularly challenging because practitioners are often meeting the family for the first time, mothers are recovering from the delivery, and families may be overwhelmed by the NICU technology and unfamiliar terminology ${ }^{[4]}$.

Empathic communication is an increasingly recognized aspect of clinical practice and is highly valued by families ${ }^{[5]}$. During the past decade, much has been written about how pediatric clinicians can share difficult information with families ${ }^{[1-4,6-14]}$. Feedback from families has further improved how healthcare providers communicate ${ }^{[15-25]}$. While there have been some reports describing practitioners' experiences and perspectives about difficult conversations ${ }^{[26-30]}$, there are limited data about views of interprofessionals ${ }^{[31-33]}$ and even fewer reports about the perspective of neonatal care providers ${ }^{[34]}$.

In this study, we sought to gain insight into providers' remembrance of and perspectives on difficult conversations in neonatal critical care. We studied written reflections obtained from interprofessional providers at the beginning of a workshop about communicating difficult news to families. By having neonatal health care professionals report about conversations that had taken place in the past while the practitioners were remote from the clinical setting, we aimed to analyze discussions that were the most memorable, and likely had the greatest impact on the providers.

\section{Methods}

Between November 2008 and June 2011, interprofessional neonatal practitioners from four Boston hospitals voluntarily attended the Program to Enhance Relational and Communication Skills (PERCS)-NICU workshops at Boston Children's Hospital (BCH). The discipline and range of experience of the attendees reflected the composition of the neonatal providers in the intensive care units. The goal of this educational initiative is to improve the communication and relational skills of neonatal practitioners who frequently need to convey difficult news. In this 6-hour workshop, participants share their experience, view and discuss an educational film about end-of-life care, and listen to a didactic presentation about conveying difficult news. A small group of participants then volunteer to communicate difficult news to family members (portrayed by actors) in a simulated environment and later discuss the conversation with the entire group. The initiative's pedagogy and efficacy have been previously described ${ }^{[35,36]}$.

At the beginning of each workshop, participants completed demographic questionnaires and were asked to "Describe an experience with a difficult conversation in the NICU that you found particularly challenging or satisfying." We allowed participants to apply their own definition to the terms "difficult conversation", "challenging", or "satisfying" so that we could elicit a broad perspective. The de-identified narrative written responses were then transcribed verbatim and entered into a computerized document. Authors DB (neonatologist and PERCS faculty member) and ECM (clinical psychologist, nurse, and PERCS faculty member) then conducted a thematic analysis of the narratives ${ }^{[37-39]}$. Narratives were initially classified as challenging, satisfying, or both. Researchers then categorized the narratives, identifying broad domains, and manually developed an initial thematic coding framework to apply to the data. Coding disagreements were reconciled through discussion until consensus was reached and final themes from the coded data agreed upon. Researchers selected text quotations that were illustrative of the themes identified from the written responses.

The BCH Institutional Review Board determined that the study met exemption criteria \#1 under the Health and Human Services regulations 45 Code of Federal Regulations 46 (i.e., research conducted in established settings involving routine educational practices). All participants voluntarily signed consent forms granting permission for their questionnaires to be used for educational research purposes.

\section{Results}

\section{NI CU conversations}

Eight-two interprofessional providers attended 8 PERCS-NICU workshops. Seventy-four participants completed narratives describing difficult conversations that they had experienced in neonatal care, seven attendees did not provide a 
narrative, and one provider recalled a conversation in the pediatric intensive care unit. The seventy-four narratives in neonatal care were written by nurses, physicians, psychosocial professionals and respiratory therapist with a wide range of clinical experience (see Table 1). Fifty-one participants (69\%) described conversations that were exclusively challenging, 22 participants (30\%) described both challenging and satisfying aspects, and one participant (1\%) described an exclusively satisfying conversation.

Table 1. Demographic Characteristics of Participants

\begin{tabular}{ll}
\hline Characteristic & Total \\
\hline Discipline, $\mathrm{n}(\%)$ & $43(58.1)$ \\
Nurse & $15(20.3)$ \\
Physician (neonatologists and neonatology fellows) & $10(13.5)$ \\
Psychosocial* & $6(8.1)$ \\
Respiratory Therapist & 74 \\
Valid N & \\
Age (years) & $24-65$ \\
Range & 41 \\
Mean & \\
Clinical Experience (years) & $1-39$ \\
Range & 15 \\
Mean & \\
Gender, $n$ (\%) & $69(93.2)$ \\
Female & $5(6.8)$ \\
Male & 74 \\
Valid N & \\
Ethnicity, $\mathrm{n}(\%)$ & $61(82.4)$ \\
Caucasian & $6(8.1)$ \\
Asian & $6(8.1)$ \\
Hispanic & $1(1.4)$ \\
Not identified & 74 \\
Valid N
\end{tabular}

*Includes social worker (1), psychologist (1), chaplain (1), and medical interpreter (7)

The length of the narrative responses ranged from one sentence (eight words) to a few paragraphs (two hundred and eight-two words) with an average sixty-word length. Sixty-two narratives (84\%) contained specific memorable conversations that had occurred in the past, ten (13\%) provided general comments about challenging conversations, and the remaining two narratives (3\%) described specific conversations involving current patients. Several responses (26\%) contained tremendous details, such as number of days the infant survived and age of the mother. A fifth of the responses revealed that the transfer of difficult news required many conversations, "We were meeting...on a daily basis and there were many ups and down, hopeful and sad moments. This emotional train went on for several months". (Medical Interpreter)

\section{Domains and themes of challenging aspects of NICU conversations}

We identified five broad domains of memorable conversations in neonatal care: Infant's Clinical Situation, Family Characteristics, Provider Characteristics, the Provider-Family Relationship, and Satisfying Elements. Within each of these domains, we identified themes that further characterized the providers' perspectives (see Table 2). Most of the narratives (81\%) contained two or more themes, illustrating the complexity of provider-family conversations in neonatal care.

I. Infant's clinical situation. Within this domain, four themes emerged regarding characteristics of the infant's clinical situation that influenced challenging conversations including: difficult diagnosis, unexpectedness, uncertainty, and decision-making. 
Difficult Diagnosis. Providers described conversations involving neonates with diagnoses of extreme prematurity, neurological issues, and/or multiple gestation.

Table 2. Domains and Themes of Memorable Conversations in the NICU

\begin{tabular}{|c|c|c|}
\hline Domains* & Themes & Sub-themes \\
\hline \multirow{9}{*}{$\begin{array}{l}\text { Infant's Clinical } \\
\text { Situation } \\
\mathrm{n}=62\end{array}$} & \multirow{3}{*}{ Difficult Diagnosis } & Neurological Issues \\
\hline & & Extreme prematurity \\
\hline & & Multiple gestation \\
\hline & \multirow{2}{*}{ Unexpectedness } & New Diagnosis \\
\hline & & Deterioration \\
\hline & \multirow{2}{*}{ Uncertainty } & Diagnosis \\
\hline & & Prognosis \\
\hline & \multirow{2}{*}{ Decision-making } & Withdrawal/withholding of life support \\
\hline & & Use of technology \\
\hline \multirow{7}{*}{$\begin{array}{l}\text { Family } \\
\text { Characteristics } \\
\mathrm{n}=30\end{array}$} & \multirow{3}{*}{ Social } & Demographics (single/teen parent, healthcare provider) \\
\hline & & Language barrier, cultural or religious characteristics \\
\hline & & Logistics (e.g., mother at different hospital) \\
\hline & \multirow{3}{*}{ Emotional } & Inability to grasp situation \\
\hline & & Anger \\
\hline & & Suffering \\
\hline & Medical & Medical (maternal illness, parental psychopathology) \\
\hline \multirow{2}{*}{$\begin{array}{l}\text { Provider } \\
\text { Characteristics } \\
\mathrm{n}=22\end{array}$} & Clinical Inexperience & Sense of unpreparedness \\
\hline & $\begin{array}{l}\text { High Professional } \\
\text { Self-Expectations }\end{array}$ & Sense of responsibility \\
\hline \multirow{8}{*}{$\begin{array}{l}\text { Provider-family } \\
\text { Relationships } \\
\mathrm{n}=35\end{array}$} & \multirow{2}{*}{ Depth of Relationship } & No previous relationship with family \\
\hline & & Close attachment with family \\
\hline & \multirow{3}{*}{ Team Approach } & Positive \\
\hline & & Negative \\
\hline & & Neutral \\
\hline & \multirow{3}{*}{ Conflict } & Between family and provider \\
\hline & & Within family \\
\hline & & Within staff \\
\hline \multirow{2}{*}{$\begin{array}{l}\text { Satisfying } \\
\text { Elements }\end{array}$} & \multirow{2}{*}{ Providing Meaningful Care } & Family’s ability to grasp situation \\
\hline & & Provider's commitment \\
\hline
\end{tabular}

$*_{n}$ reflects the number of responses with one or more of these themes

A family decided that they wanted to withdraw support on their extremely ill ex-25 week infant who also had multiple congenital anomalies. Unfortunately, [the baby did not have an] official diagnosis. -Nurse

Unexpectedness. Practitioners also expressed their anxiety about discussing with families an infant's unexpected diagnosis or unexpected clinical deterioration. 
A baby had a precipitous change in status due to necrotizing enterocolitis and the family came back after a happy day of visiting and kangaroo care to find me and the team taking care of their very sick baby. Trying to explain the change was awful. -Nurse

...(was devastating) telling a family that their baby was dying when I first met them - without enough time to slowly introduce how sick their baby was after being perfectly healthy 24 hours earlier. -Physician

Uncertainty. Providers described having an especially difficult time when there was uncertainty about the infant's diagnosis or prognosis.

I have recently cared for an infant with a possible diagnosis of trisomy 21...Working with the family while awaiting the test results was very difficult. -Nurse

Decision-Making. In many narratives, practitioners expressed significant concern about discussions involving decisionmaking, particularly around end-of-life options.

I worked closely with a family whose baby...had massive brain damage. For the next three days her parents worked to decide whether or not to redirect care, and some of the things they said and questions they asked were very difficult to hear and answer. -Nurse

...discussing end of life care for an infant that was suffering (treatment was futile), but family was not interested in redirection. -Physician

II. Family characteristics: In this domain, three themes emerged including: social, emotional and medical characteristics.

Social. Parental characteristics, such as single parenthood, teen parenthood, or parents employed as healthcare professionals, added to the degree of difficulty of conversations. Families who did not speak English as their primary language, and those with cultural or religious differences compounded communicative and relational challenges.

I encountered a situation in which a physician was describing possible complications and risks during a delivery but the physician was numb to the family's religious beliefs. - Medical Interpreter

Practitioners described additional pressure to communicate well when there were logistical challenges, such as when the infant's mother remained at the birth hospital.

Emotional. Practitioners emphasized their struggles to process the range of family's emotions. As the messengers of difficult news, providers were often confronted with and needed to address the family's grief, anger, or preferences to distance themselves physically or emotionally. For example, a nurse recalled how one family "refused to talk to the physician" after the physician had conveyed a new diagnosis of a severe intraventricular hemorrhage. Many clinicians struggled with families' inability to grasp and realistically comprehend devastating information about their infant.

I recently sat with a family in a meeting where the parents were told that their child likely had a congenital abnormality that was not compatible with life... I never got a sense of whether the parents really "got it". They asked for time alone and then left without coming back to the bedside. It felt unsatisfying because I did not get to help them process or assess their understanding. -Nurse

Discussing medical treatment options for an $\mathrm{x}$-28 week infant whose prognosis was very poor...[was] a challenging experience because what the patient's mother wanted (for us to make her baby better), was not something we were able to do. -Physician 
Medical. Maternal illness and parental psychopathology also impacted provider-family conversations.

...The mother became very anxious...and asked if the baby could survive. [It was] difficult to be honest yet comforting at this moment of high anxiety. -Nurse

...The parents were incredibly anxious and stressed and rarely left the [infant's ] bedside, questioning every aspect of his care and medical management. It was very difficult to balance respecting their rights and roles as parents with setting limits so I...could provide effective and safe care. Also [challenging] to try to figure out how to communicate the critical nature of [the infant's] diagnosis without escalating their anxiety. -Nurse

III. Provider characteristics. In this domain, two themes emerged including clinical inexperience and high professional self-expectations.

Clinical inexperience. Providers expressed concern that their own lack of experience impaired their ability to communicate effectively with families, particularly after an unexpected question or clinical setback.

...the dad called me and asked if today was the day he was going to die. This was my first experience with a patient passing. I was extremely nervous about what...to say: supporting the parents, advocating for my patient and reducing the parents suffering. - Nurse

High professional self-expectations. Many narratives reflected practitioners' strong sense of responsibility and high internal standard to "get it right."

I had to call a mother at home to tell her, her son's respiratory distress was worsening. She was unable to come in...so I felt the pressure to convey what was going on as effectively as possible over the phone. I started the conversation with "he's having a bad day". Kept it simple and then broadened with more details as I let her absorb the bottom line. I told her what we were doing to manage the issue...I also allowed time for her questions and promised to keep her updated. -Nurse

Providers described the challenge of simultaneously providing medical information, helping families adjust to the information, and being compassionate.

It was very difficult to deal with the medical care, delivering the sad news to the parents, [and at] same time, trying to offer some emotional support. -Physician

IV. Provider-family relationships: In this domain, three themes emerged including the depth of family-staff relationship, team approach, and conflict.

Depth of family-staff relationship. The lack of a previous relationship with a family was commonly identified as stressful to providers:

A preterm infant was escalating on ventilatory support overnight and I had to update a family I've never met before and prepare them for the possibility of a poor outcome...It was challenging to deliver bad news to a family whom [I've] never formed a relationship with. -Physician

At the other end of the spectrum, a close relationship with families increased the difficulty of these conversations and activated the clinicians' own emotions:

The family trusted me and we had a good relationship. It was very difficult not to fall apart watching the parents go through this devastating time.-Nurse 
Team approach. Respondents frequently referred to the healthcare team in their narratives, emphasizing the importance of team membership and interprofessional support when facing such conversations. Within these narratives, the majority were neutral or positive about teamwork, but a few described teamwork negatively.

[I took care of a] 31 week infant with hypoplastic lungs... who was dying. No one had a lot of time to bond with the family...In a very sensitive, caring but direct manner she [the neonatologist] told the parents that their baby was not going to survive. As a team, we helped the parents with their decision to hold their baby. -Nurse

Conflict. Conflicts between the family and providers, amongst the providers, or within the family, further exacerbated the difficult circumstances:

[The parents] went through five years of in vitro fertilization and this was their miracle baby. I had the feeling they felt some of the MDs and RNs wanted to stop care but the family was determined to do everything possible. -Nurse A

I was involved in a challenging family meeting....and there was conflicting...plans of...cardiology, neurology, neonatology. It was difficult to find common ground, understand the situation and make a plan. -Nurse B

I recently had an experience with the married couple of a very ill infant. The parents were split in their opinions of how to proceed and it was challenging to work through. -Nurse C

If the infant's clinical situation was further compromised by iatrogenic causes, tension between providers and families could escalate.

[A] mother was extremely irate when her infant developed...[a MRSA] infection because she felt that it was completely preventable...This mother... would ask a multitude of questions that became disruptive. Overall, she translated her anxiety into attacking the medical team...This was extremely difficult to deal with. -Physician

V. Satisfying elements: Despite the demands of these neonatal conversations, approximately a third of participants described memorable satisfying emotionally gratifying aspects of the conversations. The theme that unites and describes these satisfying aspects is practitioners' perception of providing meaningful care to families. Satisfying aspects reflected the providers' appraisal that they were able to be responsive to the family's concerns, provide honest information, achieve trustworthy relationships, help families come to terms with treatment outcomes and decisions, and create positive, lasting memories.

The parents did not want to give up... On day...forty-four, the baby had several... decompensations and we had done everything possible... I told them [that] I had never given up on Baby $\mathrm{M}$ but that today he showed me how tired he was and it looked like he couldn’t fight anymore...They thanked me for my care and honesty. -Nurse

The tube came out...and he died quickly. I spent the rest of the day with this family and their baby. We took enough pictures to fill a small album. Dad gave the baby a bath. Their pastor and mom's mother also came to visit...I felt like I really helped them and showed that their baby was real and did matter, despite only being alive for a few hours. -Nurse

When interprofessional groups were compared, sub-themes were consistent across the written narratives of physicians, nurses, and respiratory therapists but nurses tended to highlight the depth of their relationship, high professional self-expectations, and uncertainty of an infant's diagnosis and prognosis more often than the physician and respiratory therapist group. Not surprisingly, the psychosocial group discussed the family's social characteristics more frequently than any other type of practitioner. 


\section{Discussion}

The narratives shared by providers reveal the complex ecology of challenging conversations in neonatal intensive care. By thematically analyzing the narratives from neonatal providers, we have gained insight into the provider perspective about engaging in difficult conversations. As most practitioners described a challenging or difficult conversation from the past, we may have tapped into particularly memorable experiences that shaped or influenced practitioners' subsequent interactions in the NICU. Our finding that one fifth of respondents recalled multiple dialogues supports prior reports that challenging healthcare conversations are not merely about "breaking bad news", but involve a process of unfolding discussions over time that enable families to absorb information, ask questions, and develop relationships with providers ${ }^{[40,41]}$.

The uncertainty of pregnancy and birth has been shown to lead to different decision-making conversations by obstetricians and midwives with their patients ${ }^{[42,43]}$. Similarly, we found that the uncertainty of a patient's diagnosis or prognosis can amplify communicative challenges and be daunting for neonatal practitioners. Because this uncertainty can impact the content of discussions, perhaps it might impact a family’s decision-making in neonatal care.

Previous reports have shown the importance that neonatal practitioners place on providing families with understandable, unbiased and timely information ${ }^{[34]}$. We found that neonatal providers feel a strong sense of responsibility to clearly communicate the infant's circumstances to families. As presented by Antonovsky, humans need to understand stressors in order to cope with life challenges ${ }^{[44]}$. It is unrealistic to expect that families can move forward and make decisions until they cognitively and emotionally comprehend the situation. It is important for practitioners to recognize that this apparent lack of readiness by the family to hear and comprehend is not uncommon, and is often a necessary part of a family's adjustment to overwhelming news ${ }^{[4]}$. Thus, it is vital for providers to slow the pace of their conversations, broach topics respectfully, and recap the clinical course to adequately scaffold these conversations and support families.

As emotionally taxing as these conversations might be, nearly a third of providers described positive elements and felt gratified, sustained and appreciated after the interaction. Clinicians might find it helpful to recognize that there can be satisfying elements to even the most stressful conversations and to bear this in mind when approaching challenging conversations.

There are several limitations of our study. The findings of this study were limited to written narrative comments from questionnaires and these varied in both length and depth of response. Because we did not define the terms "difficult conversation”, "challenging”, or "satisfying”, we allowed for a broad interpretation of the study question. The study did not have an adequate number of responses to allow us to explore in depth the differences in themes based on provider discipline or experience. Further, as the responses were written, we were unable to probe for more detail or further clarify responses, as in typical qualitative studies that use in person methods such as interviews or focus groups. Although participants worked in four different hospitals, all of the NICUs were located in the same geographical region, and the transferability of our findings may be limited. Finally, because participants volunteered for our communication workshop, there may be a possible sampling bias with this group being more sensitive to difficult conversations than non-attendees.

These neonatal conversations are about so much more than merely transferring information. They are about crossing a threshold, engaging interpersonally and emotionally, and cultivating relationships. Such conversations cannot be scripted or completely free of anxiety, but experiential learning opportunities can help providers to feel more prepared and secure in the face of uncertainty and enhance the ability of practitioners to draw from their already existing abilities ${ }^{[36,46,47]}$. In particular, many of the communicative challenges practitioners described focused on end-of-life decision making and care, as well as conflictual relationships between families and staff and between providers. Based on our findings, educational offerings might focus on these areas.

We hope that our findings will help to attenuate some of the provider anxiety by having readers use the provider-based themes identified in our study to anticipate the difficulty of conversations. For dialogues that contain the challenging 
themes that we identified, providers could, for example, anticipate and prepare for the family's likely questions and emotional responses, customize family meetings and communicative style based on the needs and preferences of the family, and plan to have adequate psychosocial support available for families during and after the discussions. Finally, by describing memorable neonatal conversations from the provider perspective, we hope to encourage clinicians to reflect upon and continually refine their approach to communicating with families.

\section{Competing interests}

The authors declare that they have no competing interests.

\section{Authors contributions}

All of the authors listed on this paper 1) have made substantial contributions to the conception and design, or acquisition of data, or analysis and interpretation of data; 2) have been involved in drafting the manuscript or revising it critically for important intellectual content; and 3) have given final approval of the version to be published. Each author has participated sufficiently in this work.

\section{Acknowledgements}

The authors would like to acknowledge David M. Browning, MSW, BCD, Anne R. Hansen, MD, MPH, and Marilyn Ritholz, PhD for their thoughtful feedback on an earlier version of the manuscript. We dedicate this manuscript to the infants and their families whose journeys we have shared, and who have served as our teachers and guides.

\section{References}

[1] Coscia A, Bertino E, Tonetto P, et al. Communicative strategies in a neonatal intensive care unit. J Matern Fetal Neonatal Med. 2010; 23: 11-13. PMid:20836730 http://dx.doi.org/10.3109/14767058.2010.509911

[2] Fox S, Platt FW, White MK, et al. Talking about the unthinkable: perinatal/neonatal communication issues and procedures. Clin Perinatol. 2005; 32: 157. PMid:15777827 http://dx.doi.org/10.1016/j.clp.2004.11.011

[3] Laing IA, Freer Y. Reorientation of care in the NICU. Semin Fetal Neonatal Med. 2008; 13: 305-309. PMid:18486575 http://dx.doi.org/10.1016/j.siny.2008.03.009

[4] Jellinek MS, Catlin EA, Todres ID, et al. Facing tragic decisions with parents in the neonatal intensive care unit: Clinical perspectives. Pediatrics. 1992; 89: 119-122. PMid:1727994

[5] Mack JW, Hilden JM, Watterson J, et al. Parent and physician perspectives on quality of care at the end of life in children with cancer. J Clin Oncol. 2005; 23: 9155-61. PMid:16172457 http://dx.doi.org/10.1200/JCO.2005.04.010

[6] Boyd JR. A process for delivering bad news: supporting families when a child is diagnosed. J Neurosci Nurs. 2001 ; 33: 14-20. PMid:11233358 http://dx.doi.org/10.1097/01376517-200102000-00003

[7] Curtis JR, Engelberg RA, Wenrich MD, et al. Studying communication about end-of-life care during the ICU family conference: development of a framework. J Crit Care. 2002; 17: 147-160. PMid:12297990 http://dx.doi.org/10.1053/jcrc.2002.35929

[8] Harrison ME, Walling A. What do we know about giving bad news? A review. Clin Pediatr. 2010; 49: 619-626. PMid:20185480 http://dx.doi.org/10.1177/0009922810361380

[9] Izatt S. Difficult conversations in the neonatal intensive care unit. NeoReviews. 2008; 9: e321-e325. http://dx.doi.org/10.1542/neo.9-8-e321

[10] Jan M, Girvin JP. The communication of neurological bad news to parents. Can J Neurol Sci. 2002; 29: 78-82. PMid:11858541

[11] Levetown M. Facing decisions about life and death--communication with parents. Bioethics Forum. 2002; $18:$ 16-22.

[12] Price J, McNeilly P, Surgenor M. Breaking bad news to parents: the children's nurse's role. Int J Palliat Nurs. 2006; 12: 115-120. PMid:16628177

[13] Williams C, Munson D, Zupancic J, et al. Supporting bereaved parents: practical steps in providing compassionate perinatal and neonatal end-of-life care. A North American perspective. Semin Fetal Neonatal Med. 2008; 13: 335-340. PMid:18472317 http://dx.doi.org/10.1016/j.siny.2008.03.005

[14] Workman E. Guiding parents through the death of their infant. J Obstet Gynecol Neonatal Nurs. 2001; 30: 569-573.

PMid:11724192 http://dx.doi.org/10.1111/j.1552-6909.2001.tb00003.x 
[15] Baird G, McConachie H, Scrutton D. Parents' perceptions of disclosure of the diagnosis of cerebral palsy. Arch Dis Child. 2000; 83: 475-480. PMid:11087279 PMCid:PMC1718571 http://dx.doi.org/10.1136/adc.83.6.475

[16] Charchuk M, Simpson C. Hope, disclosure, and control in the neonatal intensive care unit. Health Commun. 2005; 17: $191-203$. PMid:15718196 http://dx.doi.org/10.1207/s15327027hc1702_5

[17] Clark NM, Cabana MD, Nan B, et al. The clinician-patient partnership paradigm: outcomes associated with physician communication behavior. Clin Pediatr. 2008; 47: 49-57. PMid:17901215 http://dx.doi.org/10.1177/0009922807305650

[18] Gordon C, Barton E, Meert KL, et al. Accounting for medical communication: parents' perceptions of communicative roles and responsibilities in the pediatric intensive care unit. Comm Med. 2009; 6: 177-188. PMid:20635554

[19] Hsiao JL, Evan EE, Zeltzer LK. Parent and child perspectives on physician communication in pediatric palliative care. Palliat Support Care. 2007; 5: 355-365. PMid:18044413 http://dx.doi.org/10.1017/S1478951507000557

[20] Jones L, Woodhouse D, Rowe J. Effective nurse parent communication: a study of parents' perceptions in the NICU environment. Patient Educ Couns. 2007; 69: 206-212. PMid:17936549 http://dx.doi.org/10.1016/j.pec.2007.08.014

[21] Jurkovich GJ, Pierce B, Pananen L, et al. Giving bad news: the family perspective. J Trauma. 2000; 48: 865. PMid:10823529 http://dx.doi.org/10.1097/00005373-200005000-00009

[22] Mack JW, Wolfe J, Grier HE, et al. Communication about prognosis between parents and physicians of children with cancer: parent preferences and the impact of prognostic information. J Clin Oncol. 2006; 24: 5265-5270. PMid:17114660 http://dx.doi.org/10.1200/JCO.2006.06.5326

[23] Meyer EC, Ritholz MD, Burns JP, et al. Improving the quality of end-of-life care in the pediatric intensive care unit: Parents' priorities and recommendations. Pediatrics. 2006; 117: 649-657. PMid:16510643 http://dx.doi.org/10.1542/peds.2005-0144

[24] Midson R, Carter B. Addressing end-of-life care issues in a tertiary treatment centre: lessons learned from surveying parents' experiences. J Child Health Care. 2010; 14: 52-66. PMid:20207658 http://dx.doi.org/10.1177/1367493509347060

[25] Zwaanswijk M, Tates K, van Dulmen S, et al. Young patients', parent', and survivors' communication preferences in paediatric oncology: results of online focus groups. BMC Pediatr. 2007; 7: 35. PMid:17996108 http://dx.doi.org/10.1186/1471-2431-7-35

[26] Bartel DA, Engler AJ, Natale JE, Misra V, Lewin AB, Joseph JG. Working with families of suddenly and critically ill children: physician experiences. Arch Pediatr Adolesc Med. 2000; 154: 1127-1133. PMid:11074855 http://dx.doi.org/10.1001/archpedi.154.11.1127

[27] Meier DE, Back AL, Morrison RS. The inner life of physicians and care of the seriously ill. JAMA. 2001; $286: 3007-3014$. PMid:11743845 http://dx.doi.org/10.1001/jama.286.23.3007

[28] Parker-Raley J, Jones BL, Maxson RT. Communicating the death of a child in the emergency department: managing dialectical tensions. J Healthc Qual. 2008; 30: 20-31. PMid:18831473 http://dx.doi.org/10.1111/j.1945-1474.2008.tb01158.x

[29] Rogg L, Aasland OG, Graugaard PK, et al. Direct communication, the unquestionable ideal? Oncologists' accounts of communication of bleak prognoses. Psycho-Oncology. 2010; 19: 1221-1228. PMid:20186873 http://dx.doi.org/10.1002/pon.1691

[30] Stenmarker M, Hallberg U, Palmérus K, et al. Being a messenger of life-threatening conditions: experiences of pediatric oncologists. Pediatr Blood Cancer. 2010; 55: 478-484. PMid:20658619 http://dx.doi.org/10.1002/pbc.22558

[31] Andresen EM, Seecharan GA, Toce SS. Provider perceptions of child deaths. Arch Pediatr Adolesc Med. 2004 ; $158: 430-435$. PMid:15123474 http://dx.doi.org/10.1001/archpedi.158.5.430

[32] Hall JA. Some observations on provider-patient communication research. Patient Educ Couns. 2003; 50: 9-12. http://dx.doi.org/10.1016/S0738-3991(03)00072-7

[33] Steinhauser KE, Christakis NA, Clipp EC, McNeilly M, McIntyre L, Tulsky JA. Factors considered important at the end of life by patients, family, physicians, and other care providers. JAMA. 2000; 284: 2476-2482. PMid:11074777 http://dx.doi.org/10.1001/jama.284.19.2476

[34] Coyne I, O’Neill C, Murphy M, Costello T, O’Shea R. What does family-centred care mean to nurses and how do they think it could be enhanced in practice. J Adv Nurs. 2011; 67: 2561-2573. PMid:21771044 http://dx.doi.org/10.1111/j.1365-2648.2011.05768.x

[35] Browning DM, Meyer EC, Truog RD, et al. Difficult conversations in health care: Cultivating relational learning to address the hidden curriculum. Acad Med. 2007; 82: 905-913. PMid:17726405 http://dx.doi.org/10.1097/ACM.0b013e31812f77b9

[36] Meyer EC, Brodsky D, Hansen AR, Lamiani, Sellers DE, Browning DM. An interdisciplinary, family-focused approach to relational learning in neonatal intensive care. J Perinatol. 2011; 31: 212-9. PMid:20706191 http://dx.doi.org/10.1038/jp.2010.109

[37] Boyatzis R. Transforming Qualitative Information: Thematic Analysis and Code Development. California: Sage, 1998. PMid:9729839

[38] Guest G. Applied Thematic Analysis. California: Sage, 2012. 
[39] Pope C, Ziebland S, Mays N. Qualitative research in health care: Analysing qualitative data. BMJ. 2000; 320: 114-116. Mid:10625273 http://dx.doi.org/10.1136/bmj.320.7227.114

[40] Mundy CA. Assessment of family needs in neonatal intensive care units. Am J Crit Care. 2010; 19: 156-163. PMid:20194612 http://dx.doi.org/10.4037/ajcc2010130

[41] Truog RD, Christ G, Browning DM, et al. Sudden traumatic death in children: "we did everything, but your child didn’t survive. JAMA. 2006; 295: 2646-54. PMid:16772628 http://dx.doi.org/10.1001/jama.295.22.2646

[42] Matthias MS. Problematic integration in pregnancy and childbirth: Contrasting approaches to uncertainty and desire in obstetric and midwifery care. Health Comm. 2009; 24: 60-70. PMid:19204859 http://dx.doi.org/10.1080/10410230802607008

[43] Matthias MS. The impact of uncertainty on decision making in prenatal consultations: obstetricians' and midwives' perspectives. Health Comm. 2010; 25: 199-211. PMid:20461605 http://dx.doi.org/10.1080/10410230903544977

[44] Antonovsky A. Health, Stress and Coping. San Francisco: Jossey-Bass Publishers, 1979.

[45] Kubler-Ross E, Kessler D. On Grief and Grieving: Finding the Meaning of Grief Through the Five Stages of Loss. New York:Scribner, 2005.

[46] Lamiani G, Barello S, Browning DM, et al. Uncovering and validating clinicians' experiential knowledge when facing difficult conversations: a cross-cultural perspective. Patient Educ Couns. 2012; 87: 307-12 PMid:22196987 http://dx.doi.org/10.1016/j.pec.2011.11.012

[47] Waisel DB, Lamiani G, Sandrock NJ, et al. Anesthesiology trainees face ethical, practical, and relational challenges in obtaining informed consent. Anesthesiology. 2009; 110: 480-486. PMid:19225393 http://dx.doi.org/10.1097/ALN.0b013e318197ff46 